Session number : 2238

\title{
The Design Challenge Program in Support of the Engineering Design Graphics Course
}

\author{
Satyajit Verma \\ Texas A \& M University - Corpus Christi
}

Educators strive to empower students by providing them with a wide set of skills, so that they may become effective contributors to the society and their employers. These skills include not only an understanding of scientific and engineering principles along with their applications, but also skills to interact smoothly and effectively in human environment. These skills ensure that our graduates will be able to achieve their personal and their employers' desired goals and objectives. These expected characteristics of the graduates are captured in the list of expected outcomes in the ABET Guidelines for Engineering and Engineering Technology Programs ${ }^{1}$.

The first level of an Engineering Design Graphics course, as normally taught in many two year and four year colleges and universities, leads a student through the steps in the development of an industrial product. These steps range from idea generation to the final product specifications. Along side, and equally important, the students learn the standard methods of interpreting and creating engineering drawings. Usually, the students work in teams and either pick projects of their own choice or one assigned by the course instructor. The normal duration of the project is one semester. The final product is often a set of detailed working drawings suitable for fabricating the product. The working drawings are prepared by computer graphical methods such as AutoCAD. As the students work in teams, they conduct group meetings, prepare project reports and make presentations on their projects.

The TSGC program provides a format comprising milestones during the progression of the course. It formalizes the curriculum structure, assists in its progression, and serves as a third party confirmation of the curriculum activities.

Outline of the Engineering Design Graphics Course Taught at TAMU-CC

The Design Graphics course as taught in many institutions, contains elements of engineering drawing practices and manufacturing practices. The format of the course contains the steps in a typical design process in the development of a product. The steps are generally described as follows:

1. Problem Identification

2. Preliminary Ideas (Brainstorming, Sketching)

3. Refinement Considerations

4. Design Analysis

5. Decision (Writing Reports, Making Presentations)

6. Implementation 
Details of the above steps can be found in the text-book ${ }^{2}$ for the course. Concurrent with the above steps during the semester, the students learn the details of standard practices in engineering drawing. The students use a workbook ${ }^{3}$ for drawing by hand as well as the latest version of Autodesk's software for developing computer graphic skills. There are many types of software available for making engineering drawings on the market. Texas A \& M University Corpus Christi uses AutoCAD 2002 because of its wide acceptance in the industry. Some of the important topics covered in the engineering graphics part of the course are:

1. Freehand Sketching

2. Orthographic Projections

3. Auxiliary Views, Sections

4. Dimensioning, Tolerances

5. Working Drawings Set

6. Three Dimensional Pictorials (Oblique and Isometric)

Throughout the semester, the students work in groups of two to four students to prepare final design drawings and reports on their projects. Typically, the students write one final report per team during the semester. In some case the students may also build a prototype.

\section{Outline of the TSGC Design Challenge Program}

The Texas Space Grant Consortium (TSGC) administers the Design Challenge Program ${ }^{4}$ sponsored by NASA. It is intended to provide the student teams with an opportunity to engage in scientific research, hands-on design, meeting presentations, career opportunities with NASA, and educational / public outreach activities. It provides the undergraduate students with a unique opportunity to choose projects from a list of topics of interest to NASA and its contractors, and design imaginative solutions for the projects. The student teams are paired with a faculty advisor - who in this particular case was the author. Each team is assigned a mentor from NASA, usually the person who initially sponsored the project. Teams are also encouraged to seek a local collaborator to tap into his / her practical wisdom. The collaborator is someone outside of the curriculum, preferably someone in industry. The students chose the following three projects from the list of twenty eight projects provided by TSGC:

1. Solar Powered Operation of Golf Carts

2. Solar Powered Operation of Bicycles

3. Design of a Meal Tray for Use in the International Space Station.

Teams were directed through a series of Design Levels and Option Areas (See Table I). Incentives were available to the participating teams as they completed various levels, in the forms of certificates of participation, program T-shirts, patches, monetary awards, and travel grants. The Design Challenge process culminated in presentations of the proposed designs as AutoCAD drawings to a gathering of academic and NASA professionals at the TSGC Design Challenge Showcase. The level of complexity of the design projects presented at the Showcase corresponded to the academic experience of the students, and in keeping with the course contents. Thus some teams had worked two semesters on the project and some teams planned to work an additional semester on the project. 
Details of the program, participation guidelines and the schedule may be obtained from the TSGC website ${ }^{4}$. The whole program is fairly comprehensive. Only an overview is provided in this report.

The basic levels and option areas for the Design Challenge are given in Table 1. The reporting requirements during the semester may be summarized as follows:

1. Design Brief

2. E-mail updates every Tuesday

3. Full Proposal

4. Mid-term Progress Report

5. Final Report

6. Presentation at the Design Challenge Showcase (Poster Presentation and Oral Presentation)

Participation in the program was initiated by the student teams when they submitted outlines called Design Briefs - of their proposals. The Design Brief had the following four elements:

1. Team Members List

2. Project Description

3. Proposed Budget, and

4. Project Timeline

Within four weeks of submitting the Design Brief, the teams were required to submit a full proposal, containing further details of the project. By then the team had finished brainstorming possible solutions and had developed a set of criteria against which to evaluate the potential solutions.

The full proposal had the following elements:

1. Section I : Cover Page, Table of Contents, List of Figures

2. Section II : Abstract, Background, Design Objective, Design Plan

3. Section III : Time Table, Budget Plan, Team Profile

4. Section IV : References / Bibliography, Appendix

The mid-term report and the final report had the same structure and were built up gradually on the full proposal. The full proposal was reviewed by two graduate students at University of Texas, Austin. The reviewers commented on the grammar, syntax, logical thinking, presentation style, and contents of the report in general. Thus the student teams received valuable feed back on their reports.

At this level, the teams qualified for reimbursable funds for legitimate expenses. They were also awarded their choice of books and DVD on various subjects, e.g. education, career development, and NASA related activities.

During the following four weeks, the teams entered the design analysis phase and narrowed their design choices to one or two possibilities. A midterm report was due at this time. Once again, 
the report was reviewed by graduate students and valuable feedback was provided to the teams on the report.

Finally, in the next fours weeks, near the end of the semester, the teams had finalized the design, prepared the design package, and in some cases made a prototype. The final report was due at this time. A Challenge Showcase meeting was held where the teams presented their solutions to a gathering of faculty and student teams from other participating institutions, NASA mentors, collaborators, and other interested technical and administrative personnel. Outside visitors, such as students' parents, also attended.

Throughout the semester, the teams sent short e-mails every Tuesday on their weekly progress to the TSGC coordinator - hence the name Tuesday Tag-up!

The formats for the initial proposal (Design Brief), full proposal, mid-term report, final report and the Tuesday Tag-ups are provided in detail on the website. The roles and responsibilities of team members, team leader, faculty advisor, NASA mentor and the collaborator are also elucidated on the web. All this is an excellent help to the faculty advisor as well as to the students.

Much of the communication between the team members, NASA mentors and TSGC coordinator ( e.g. Tuesday Tag-ups) was carried out through e-mails. The faculty advisor was kept in the loop in all communications.

The students were also encouraged to interact with local area schools and community. These activities (Option Areas) are considered as extra effort and participation in these activities qualify the teams for additional cost reimbursable funds. Optional elements include : presentations at the area high schools, preparation of age appropriate activities suitable for elementary or middle school children, and construction of a website highlighting the project.

Team members also prepared and submitted a one page resume - called a resume brief. The compiled resumes were posted to a web-based Resume Book available to NASA engineers and contractors. Thus the students had an opportunity to be spotted for internships and summer jobs.

Members of the teams attending the Design Challenge Showcase also received promotional mementos from the program sponsors and contractors. They also toured the Johnson Space Center work facility. As an added bonus, our department had a semester end social where we displayed the project reports, brief video tapes of their presentations, and the various awards earned by the teams e.g. T-shirts, books, DVDs, patches. Students were encouraged to bring their friends and relatives to share their achievements with them. These activities provided additional exposure to this TSGC / NASA educational program.

Conducting the Design Challenge and Design Graphics Course in Parallel

The design graphics class met three times a week (Monday, Wednesday, Friday) for two hours each. This accounted for a total of 44 scheduled days in the semester excluding one day for the Final exam and one week for the spring break. The schedule of topics and group activities is 
shown in Table 2. The schedule is fairly aggressive - specially considering that most students are recent high school graduates and, many have not been exposed to situations where they are required to meet many rapidly approaching deadlines and work with groups of people unknown to them.

Given the tight schedule, the students were given crash courses in the following topics along with the technical subject matter:

1. Team Dynamics 5 :

What makes a team, how to be a team leader and how to be an effective team member.

2. Meeting Dynamics ${ }^{6}$

Elements of a productive meeting, how to conduct an efficient meeting, how to take meeting minutes.

3. Report Writing

Elements of a technical report.

4. Presentation Skills

Elements of an Effective Oral Presentation. How to Prepare a presentation on a technical report.

In most cases, one class meeting was spent on each subject matter and handouts were distributed. This activity was meant to be more of an exposure and orientation for the students, rather than an in-depth coverage of team dynamics and meeting facilitation skills.

As the semester progressed, the students faced other challenges as well:

Team Size: There were a total of twenty-four students at the beginning of the class. Anticipating that some students would drop out during the semester and some students would not work as hard as others - three teams of eight students each were formed in the beginning. Some students did drop out - and the team sizes were not equal at the end of the semester. One team still had eight members, the second team had six members, and the third team had only four members left. The idea of working on NASA projects was highly appealing to the students - however, they were apprehensive about their preparedness and competition from senior students from other universities.

Team Responsibilities: The students were allowed to choose from among themselves at least three officers: team leader, team facilitator, and minute taker.

Team Dynamics: As one would expect, the team functioning during the semester was not free of interpersonal conflict. There were team members, who would not attend team meetings, some others would not carry their share of the assigned workload; and still some others who would passively resist the team leader. In this regard, the students did get a good dose of what happens in real life team situations. The instructor interjected and guided the team members and leaders to remain focused on the work to be done and resolve the situations objectively.

Grading: The project report and presentation portion of the course was allocated twenty percent of the overall course grade. At the end of the semester, team members graded each other 
confidentially on the perceived percent contribution of each team member toward the project. Team members had a choice of making the Showcase presentation as a tag team. Thus each student had the opportunity to make the presentation and gain extra credit. However, some students still opted out. Students who made the poster presentations also earned extra credits points.

Conclusion

The program is somewhat intensive if the teams wish to accomplish all levels in one semester. For freshmen students this is certainly a challenge in terms of time management, work efficiency and working in groups. However, the overall experience is both very valuable and rewarding. The team formation can be improved by distributing the senior students among the teams.

In summary, the pairing of the TSGC Design Challenge guidelines with the Engineering Design Graphics course is a win - win combination. Teaming up with the TSGC provides some very valuable and necessary experience to the participating students. In addition to learning the nuts and bolts of engineering design graphics and AutoCAD, the students received the following benefits:

1. Learn the basic elements of a technical proposal and how to write one.

2. Valuable feedback on the style, grammar, consistency and the logistics of a scientific proposal.

3. Opportunity to make oral and visual presentations and engage in questions - answer session with NASA professionals and academicians.

4. An opportunity to see the quality of presentations of teams from other participating universities. Freshmen / sophomore students get an opportunity to see the level of complexity of projects done by the junior / senior students, and recognize what is expected of them later on.

5. Tangible awards such as books and DVDs upon completing various Levels and Options. Additional souvenirs from NASA contractors upon attending the Challenge Showcase.

6. An opportunity for internship with NASA and NASA contractors through listing in the resume book.

\section{Acknowledgements}

The author wishes to thank Ms. Debbie Mullins, the TSGC Program Coordinator, for her expert help in coordinating the program and funds. Thanks also are due to Dr. Tim Coppinger, Texas A \& M University - Corpus Christi, who has taught the course for many years, for his timely help and advise on many occasions.

\section{References}

1. 2002 - 2003 Criteria for Accrediting Engineering Technology Programs, Technology Accreditation Commission, Accreditation Board for Engineering and Technology, Inc.; Criteria 1 and 2.

2. Engineering Design Graphics AutoCAD 2000, James H. Earl; 10 ${ }^{\mathrm{th}}$ Edition, Prentice Hall 2001. 
3. From Sketchpad to AutoCAD; Gerald E. Vinson; Kendall / Hunt Publishing Company 2000.

4. TSGC Design Challenge website http://www.tsgc.utexas.edu/challenge.

5. Lynn Bellamy, Barry McNeill; Texas A \& M University Team Training Workshop, 1994.

6. Meetings, Bloody Meetings [video recording] / Video Arts Ltd. ; written by John Cleese and Antony Jay ; directed by Peter Robinson; Publisher Video Arts, c1993 Chicago, Ill.

\section{Biography}

SATYAJIT VERMA, Ph. D.

Currently an assistant professor in the Mechanical Engineering Technology Program at Texas A \& M University Corpus Christi, Satyajit Verma received his Ph.D. in Chemical Engineering from Louisiana State University, Baton Rouge. He has more than 20 years of experience as product development and process development engineer in the plastics industry. 

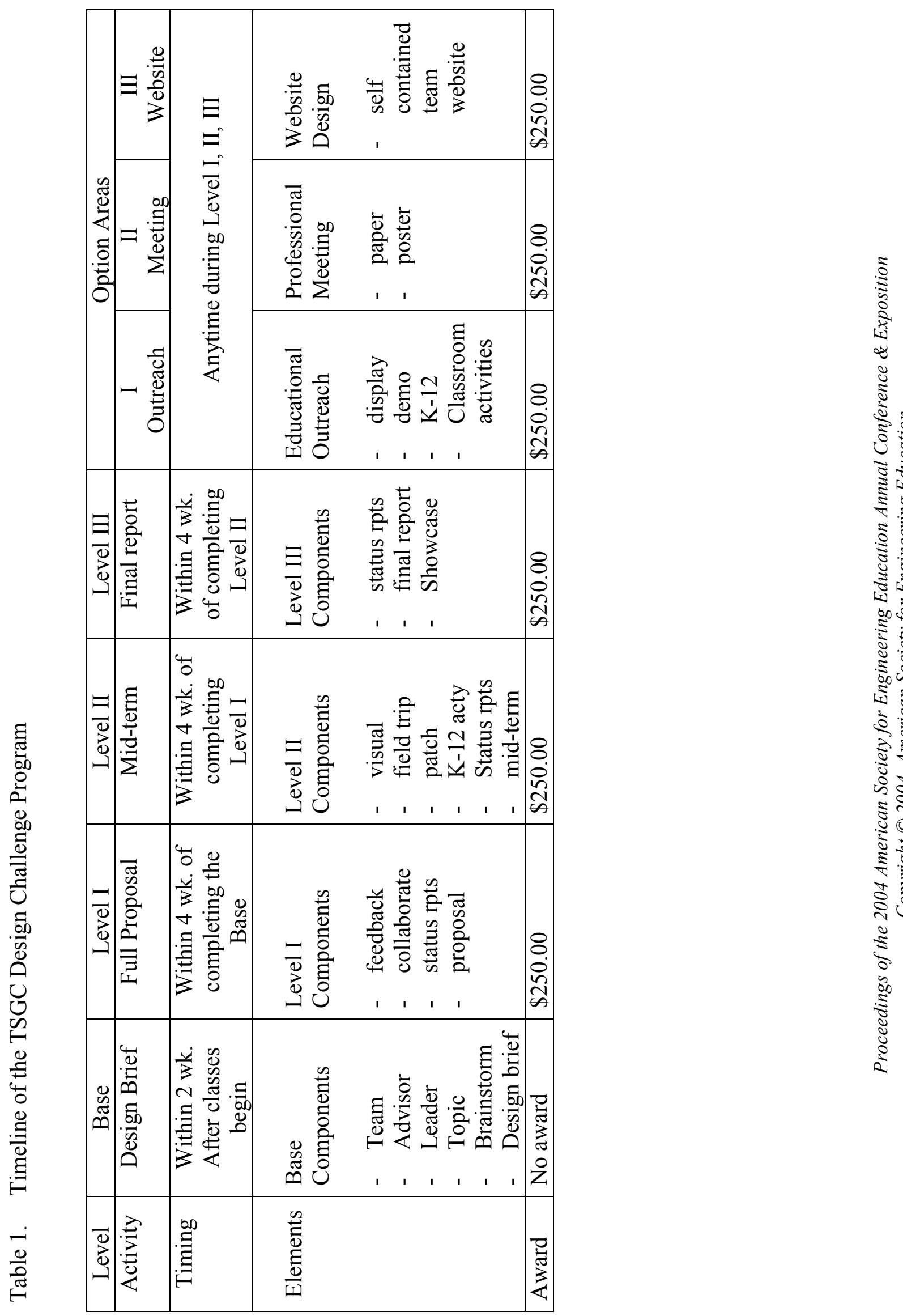


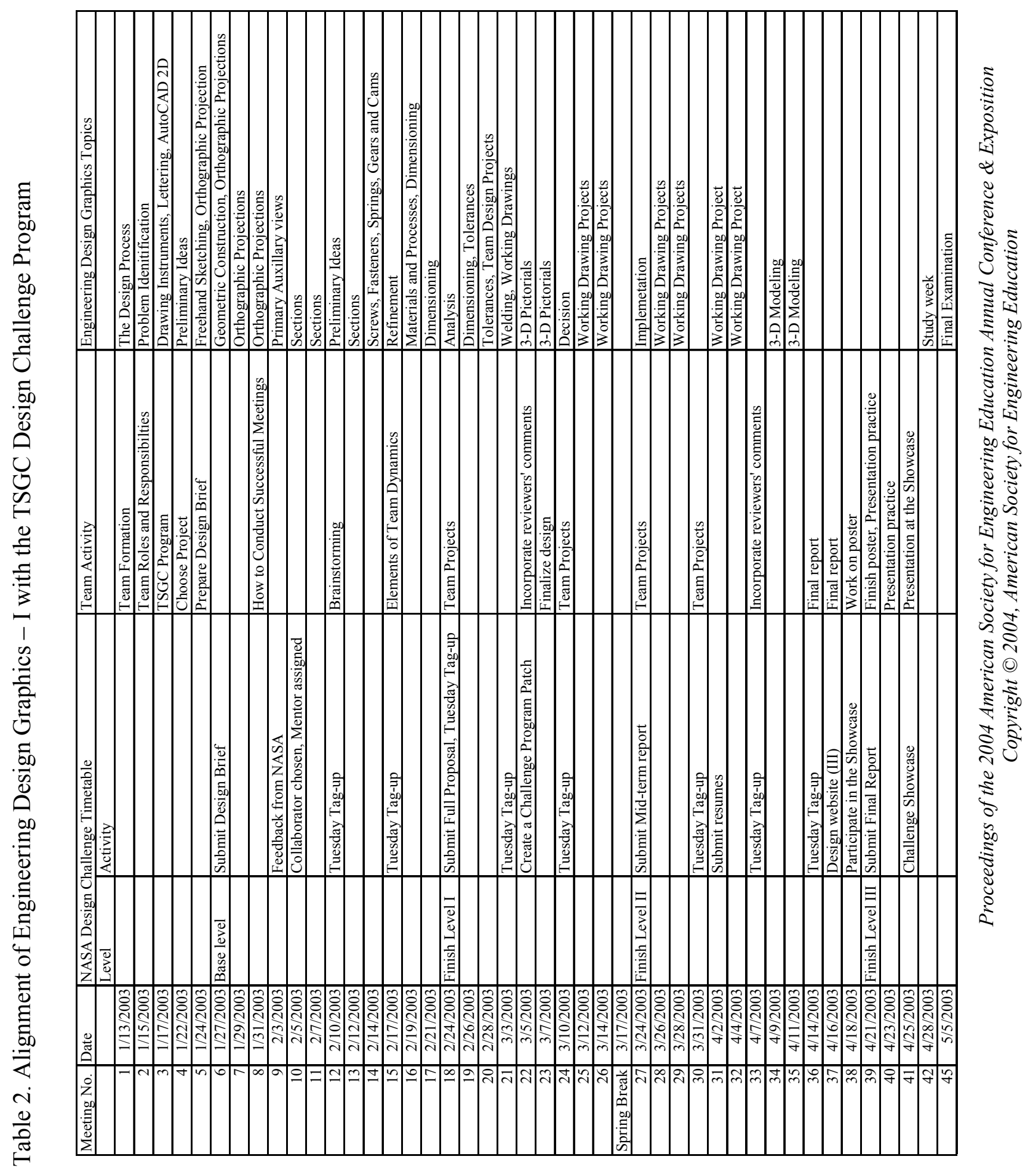

